\title{
Casteism Among Indian Doctors: A Critical Review
}

\section{Arindaam Arjunrao Pol}

Department of Radiodiagnosis, A. J. Institute of Medical Sciences and Research Centre, Mangalore, India

\section{Email address:}

arindampo1458@gmail.com

\section{To cite this article:}

Arindaam Arjunrao Pol. Casteism Among Indian Doctors: A Critical Review. World Journal of Public Health. Vol. 5, No. 4, 2020 , pp. 99-104. doi: $10.11648 /$ j.wjph.20200504.14

Received: November 17, 2020; Accepted: December 3, 2020; Published: December 8, 2020

\begin{abstract}
In India, caste-based differentiation is directly related to the socio-economic and socio-cultural status of an individual. In the past studies have shown that people's health outcomes are related to their social group and position in the social gradient. India has witnessed the suicide of promising doctors who were alleged to bullying because of their caste. The social evil called casteism is spreading its branches in every level and sector. But the disappointing fact is that no policy or norms or planning or agenda can uproot it. As it is embedded in the subconscious mind of civilians and is carried over generation after generation. The present review tries to point out in detail the presence of casteism among the Indian healthcare system. Moreover, this study also discussed if this caste-based system also discriminates patients from getting the healthcare facility. In this review all the past and present literature were searched extensively and then the finding of all the studies were discussed in a comprehensive manner. The result of the study showed that at present Indian health service system is not at all equipped with the addressing the casteism among doctors and other healthcare sevice providers. An important option could be increasing the number of dalits in the different level of healthcare sector. Weather implication of this option in practical scenario is possible that needs further evaluation. Making policies that ensures the adequate representation of members of excluded communities in healthcare can certainly reduce the cultural discrimination and prejudice.
\end{abstract}

Keywords: Casteism, Healthcare Sector, Doctor, Dalit, Discrimination

\section{Introduction}

Casteism in India refers to Barna or jati i.e, race or ethnicity which is directly related to the socio-cultural and socioeconomic status of a person. It is also influenced by religious practices and belief system that prevails in a country like India where people from more than 5 religion lives together peacefully. Hindu caste system is very complicated as the main four castes Brahmins, Kshatriyas, Vaishyas, and Shudras are subdivided into 3000 castes each and they are further subdivided into 25,000 subcastes based on their occupation mainly. And surprisingly there is the existence of Dalits or untouchables they are completely compartmentalized and suppressed by the above said four castes. "Dalit" is a Sanskrit word which means divided or split. Inter caste marriages have uplifted many Dalit and lower caste women into upper caste as in India the children get their identity of caste from father, not mother [1]. Though the practice of untouchability is forbidden by the Indian constitution but in 2020 also society is not free from it.
According to a report from the Hindustan Times newspaper, many patients are still hesitant and refuse to be treated by a Dalit doctor in Tamilnadu in India [2]. In 2019, a 26 yr old lady doctor from Mumbai committed suicide due to caste discrimination and harassment by her seniors at the workplace. These incidents are the open evidence of the prevailing casteism which is hindering the healthcare services and creating obligations to medical practitioners in India [3].

Despite obstacles, many Dalits came out with their talent and capabilities and topped in their field. The Indian caste system is one of the oldest social stratification systems in the world which represents social hierarchy based on caste. It still exists in many parts of India, not only in remote villages but also in metro cities as it is a deep-rooted concept and belief system. Due to the reservation of backward castes in higher education and growing urbanization, the so-called lower castes are coming up with more success and money and slowly the caste discrimination is broken down with the inter-caste marriages and money power in society. Poverty is a complex issue which has multidimensional aspect such as 
caste, social exclusion, denial from healthcare, education, and polity, and many more [4].

\section{Caste System in India}

The caste system is deeply rooted in Hindu philosophy and religion. The Indian caste system is evident for its unique social restriction and social stratification. Sankaran et al. (2017) have shown in their study that caste identity and social identity are interdependent and interrelated in India and it gives self-esteem as the majority of people are conscious about caste [5].

According to Bhagavad Gita (4:13), social division, or Varnashrama was based on qualities and activities (Gunakarma). Previously Brahmins were known for their higher intellectual abilities and the Shudras were known for their physical strength and endurance. But now a day the scenario is not like that as all the caste and genes got mixed due to inter-caste marriages are no one can be called superior or inferior. Ashwin Kumar (2005) had shown in his study that the caste system is present in India from the pre-modern period till the present day and socio-economic factors are the keys to social stratification [6].

The caste hierarchy in India was a pyramidal system where in the very higher position resided Brahmins. Brahmins were priests and mostly were associated with academic duties. Kshatriyas were rulers and warriors and were mostly associated with war and other administrative works. Vaishyas were mostly merchants, farmers and artisans. The last one in the caste hierarchy was sudras. They were servants and laborers. Dalits were regarded as the outcasts and untouchables. They did not even belong to the Hindu caste hierarchy (Figure 1) [7].

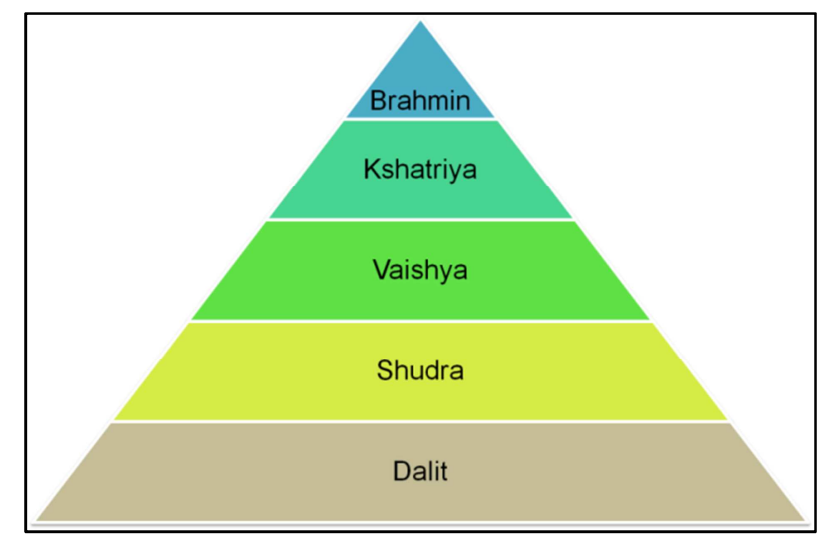

Figure 1. Caste hierarchy in India.

All men have equal potential and capabilities to flourish. In ancient times Rishis or saints were at the top of social hierarchy, but surprisingly all of them were not from Brahmin origin. Rishi Valmiki was a Shudra and Rishi Ved Vyas was a born fisherman. Now a day caste system is birth based which is originated about 1600 years ago as stated by Majumdar (2016), a scientist at NIBMG (National Institute of Biomedical Genomics) Kalyani after rigorous analysis of genetic materials [8].

Mac Iver had defined caste as a social status that cannot be changed. H. Cooley had stated it is as hereditary social class. According to Green caste is the rarely mobile feature of the rigid social stratification system. Changing the caste occupation is not supported by the Hindu caste system but officially all are protected by Human Rights. So whenever wherever a boy or a girl from the so-called lower caste goes for higher education, they face a silent teasing from teachers as well as from classmates. The caste system is a great obstacle for national unity and communal harmony. Justice is often denied and feeling of equity and brotherhood is hampered due to casteism.

During British Raj, caste discrimination was at its top as the British rulers appointed only Brahmins at their highest position of official works and lower castes as maidservants. After independence in 1947 slowly the whole nation stands against caste discrimination and as a result, Dr. B. R. Ambedkar, a born Dalit, wrote the Indian constitution in which caste discrimination was banned by laws [9]. Not only ignorance and dishonor but also violence and criminal activities come with caste discrimination. It also reduces the dignity labor and it is anti-democratic.

\section{Caste-Based Discrimination in Healthcare Services}

The caste system is a socio-cultural concept that has no such a proven genetic basis. Though it is similar to the racial system in which fair skin color gets priority and higher status than brown and black skin color. According to The Hindu newspaper report, Dalits are the main victims of communal violence and poor accessibility to healthcare services. According to the National Family Health Survey, in a lower caste, there is a tendency of not using contraception, and access to maternal care and child care is also less. It can be said that the majority of lower caste persons belong to rural India. But due to migration in search of work they are also present in a large quantity in metro cities. Altogether the scenario is controversial regarding healthcare services as strong evidence is required to make a concluding statement on it [4].

According to a report by Times of India newspaper in 2019 , especially lower caste women are sexually harassed and abused in many parts of India and despite giving many benefits from education to jobs scheduled castes (SC), scheduled tribes (ST) and other backward castes (OBC) are still denied the basic civil rights in many areas which are a curse for our society. Unknowingly and unintentionally majority of Indians practice casteism whether they admit it or not. The suicide of a Dalit student, a Ph. D. scholar of Hyderabad University, Rohith Vemula in January 2016 and suicide of a doctor, a postgraduate trainee of gynecology of a Mumbai hospital, Payal Tadvi from Bhil tribal community (ST) in May 2019 are evident to caste discrimination at that level. 
Caste is very much linked with the socio-economic status that is a big reason for the vulnerability of the ill health of lower caste people. Caste in India is a strong determinant for social exclusion and exploitation which is seen in many social science research papers. In a study, it is seen that waiting time at non-emergency healthcare services has proven the presence of social class and strong casteism [10].

In the same study, it is also said that socio-demographic factors like basic education, family income, geographic location, etc. are also linked with waiting time at healthcare services. They have proved that lower social caste has longer waiting times at non-emergency healthcare services [10].

Surprisingly this caste-based discrimination is seen only in private healthcare services. In rural India, untouchability is greatly practiced and upper caste like Brahmins are given God-like status. Still, inter-caste marriages are called shameful events and are not accepted happily. The so-called general caste or upper caste enjoy the honor of being general caste and they show their anger in open forums towards backward caste as in education and employment, seats are reserved for SC, ST, and OBC [11].

In another study conducted in Bangladesh showing clear inequalities of healthcare services and the Dalit population is badly affected by poor health status [12]. In a study, it is shown that in Uttar Pradesh rural Hindu women faced difficulty in getting maternal healthcare services due to caste barriers [13].

Many studies have conducted on the relationship between social exclusion and ill health of Dalits and tribal people and the evidence came out as positive correlation is present. Investigations were done on experience of healthcare services by Dalits people and again a hint of discrimination comes at every stage from doctors to pathologists to nurses [14].

Inequality in healthcare is common in many of the societies. In USA race-based healthcare services inequities are very much strong and prominent. This structural racism affects the population from grass root level to the top level [15]. This race-based discrimination mainly is based on the skin color of an individual.

On the other hand, in India this race-based inequality is been replaced by the caste-based systems. In lower castes the rate of infant mortality is higher compared to the upper castes. High infant mortality is evident in poverty, illiteracy, and unemployment. The economic and social disparity is the root cause of differential healthcare services at multi-levels [16]. It is also shown in many studies that the financial burden and economic stagnation are responsible for differential healthcare services.

\section{The Marginalization of Patients: Inequity in Healthcare}

Unequal access to healthcare services in India is a prominent research topic for many decades. Though there are many barriers to it apart from casteism, casteism is a curse for all societies and a democratic country like India. Poor housing, lack of balanced nutrition, unsafe drinking water, lack of sanitation awareness, and the use of biomass fuels increase the risk of having poor health and diseases in marginalized communities [17].

The infrastructure of healthcare and the economic condition of the patient is equally important as acceptability and mental setback. Casteism is such a disease in which a higher caste imposes ignorance and disrespect for lower caste and also lower caste hesitates to approach for any facilities and services due to inferiority complex. Provision of free medicine is present in almost every state but patient utilization rate is low. The reason behind this is not at all clear. Access to healthcare is opposite in rural and urban India. But the disease burden and morbidity is increasing every day in India due to many reasons. In a study, it is shown that socio-environmental factors affect the health of the patients a lot especially for the disadvantaged and backward class of society [18].

In a study it is shown that multiple discrimination and access barriers are present is a marginalized community of rural and remote areas which causes a serious problem in Australia [19]. Health equity is a serious concern worldwide. In Canada also social exclusion and discrimination based on origin are seen in healthcare service which is no doubt a social curse [20].

In India- Canada collaborative research suggesting especially lower caste women and marginalized indigenous groups are vulnerable and victims of discrimination at not only healthcare but also education, employment, and landowning [21]. Maternal healthcare is still not available fully for SCs and STs in India which is a serious concern [22]. Upon investigation by government and other bodies the reason comes up as geographical barriers, women's education and awareness, family income, etc. but if we see at grass root level, we often will end up seeing casteism.

In another study, it is prominent that women and Muslims in rural north India are the victims of the poor healthcare system with unqualified so-called doctors at primary healthcare centers [23]. There arises a question for policymakers and decision-makers of India, minorities, and other lower caste of rural India especially women, how long they will be ignored and victimized. There are many challenges to healthcare in India like lack of access and awareness, deserved manpower crisis, affordability, and lack of accountability which is causing serious damage in our economy and society [24].

Young doctors often refuse to be posted in villages and remote areas that is another aspect for many decades. On the other hand, often institutional deliveries and postnatal care are refused to the lower caste Dalit family and the reason shown by the authority that medical staff is not present at that moment. This is the reason behind maternal death and infant death in rural India.

In a study conducted by Baraik and Kulkarni (2014) it was highlighted how the nutritional status among dalits and avivashis are prominent across India in comparison with the other higher castes. This study has also pointed out higher 
risks of death among these two populations in the rural and urban areas [25]. In another study the same findings were reiterated.

Dasgupta and Thorat (2009) have stressed that among the adivashis the immunization rate is the lowest followed by Dalits compared to the other higher castes [26]. The same reality was also reflected on the data published by National Family Health Survey-3 (NFHS-3). In this survey it was mentioned that among Adivasis and dalits the antenatal care and the rate of institutional birth remains lowest. This survey also reported that Adivasis remained most deprived caste when it comes to healthcare [27].

\section{The Distinction Between Healthcare Professionals}

Though a reservation is there is all sort of higher education in India but the majority of the seats reserved for ST remains vacant. The reason behind it is mainly lack of access and lack of acceptance in the high school level. Even the Anganwadi Centers also sometimes refuses a Dalit person to enter. From rural India, lots of nurses and assistant nurses come from lower caste background but they often face humiliation and harassment at city hospitals.

According to the report of National Rural Health Mission 2015 , childbirth at home with a skilled person is a common practice in many states, and childbirth by family members or unskilled person is also practiced in Bihar and Uttar Pradesh which is dangerous and risky for both mother and child. Intergroup disparity is also prominent in Karnataka and Tamil Nadu. According to a study, in a village in Karnataka Dalit patients are neglected in terms of misbehavior and improper treatment by doctors and nurses but on the other hand, nonDalits are treated more cordially and given more time and care [27]. Caste-based differential treatment is present not only in Karnataka rather everywhere in India. An upper-caste doctor is always accepted by society and an upper caste patient is always treated properly in terms of more time and more attention by doctors.

Casteism often leads to harassment and poor social acceptance in various community circles and centers. The medical fraternity is badly affected by casteism at colleges, hostels, and later at the workplace by seniors. Not only students of medical colleges but also teachers comment like $\mathrm{SC} / \mathrm{ST}$ students do not deserve to study medical despite they perform well [28].

Casteism is such a sensitive issue that gathering evidence or investigating independently is very difficult. The only reliable source is newspapers and news channels from where we can get information and visualize the real scenario. Though caste discrimination is not only present in the medical field but also present in all premiere institutes especially in engineering and management. A Dalit doctor from Tamil Nadu attempted suicide in the year 2017 but survived somehow was also a victim of casteism [29]. Surprisingly only a few extreme cases or incidents come up as news headlines. There are numerous cases in which the caste victims experience depression and frustration in the higher education field.

The data from NSSO showed that presence of dalits in the healthcare sector is lesser than the other higher castes and this difference is more prominent in rural areas. Except in nursing and in midwifery the proportion on dalits are more (Table 1). The upper and middle level castes are included in the other category and data clearly highlight the overrepresentation of these castes in the healthcare sector, especially in general medicine practitioners and specialist doctors. This underrepresentation is also prominent in associated healthcare sections. there is an underrepresentation of radiologists, lab technicians and other associated health professionals from dalits and adivasis [27].

Table 1. Percentage of Health Professionals (except nursing/midwifery) across social group in rural India, (adapted and modified from NSSO 68th round, employment and unemployment, 2011-12 [30].

\begin{tabular}{llllll}
\hline State & ST & SC & OBC & Others & Total \\
\hline Punjab & - & 67.50 & - & 32.50 & 100 \\
Haryana & - & 65.35 & 7.85 & 26.79 & 100 \\
Rajasthan & 5.25 & 36.02 & 2.00 & 56.73 & 100 \\
Uttar Pradesh & - & 10.74 & 65.11 & 24.14 & 100 \\
Bihar & - & 1.77 & 88.79 & 9.45 & 100 \\
West Bengal & 3.25 & 9.60 & 4.70 & 82.46 & 100 \\
Orissa & 12.64 & 5.19 & 33.12 & 49.05 & 100 \\
Madhya Pradesh & - & - & 74.01 & 25.99 & 100 \\
Gujarat & - & 24.74 & - & 75.26 & 100 \\
Maharashtra & - & 19.67 & 4.52 & 75.81 & 100 \\
Andhra Pradesh & - & 6.44 & 51.32 & 42.23 & 100 \\
Karnataka & - & 13.90 & 65.66 & 20.44 & 100 \\
Kerala & - & 20.17 & 55.34 & 24.49 & 100 \\
Tamil Nadu & - & - & 100 & - & 100 \\
\hline
\end{tabular}

\section{The Way Forward}

World Health Organization (WHO) is working throughout the globe to improve daily life and spreading awareness among the backward class/caste. An organization like the World Bank gives funds regularly for education, nutrition, and healthcare services for the backward classes of developing countries. The agenda like the National Rural Health mission is there to provide support. Above all, there is a need for change in psychosocial behavior among doctors as well as among patients irrespective of caste, creed, and socioeconomic status. Sensitization of healthcare workers regarding all types of discrimination targeted health education and outreach programs and community levelspecific interventions are required for an effective healthcare system to work [31]. Rural India needs more able hands to help people without discrimination.

Eradicating poverty to some extent can diminish caste discrimination. The idea poverty comes with the population explosion, unemployment, migration, education, etc. and all are equally serious issues to look upon. Upward social mobility of individuals and gaining skills in various areas can 
be fostered so that nobody can dishonor the dignity of selfrespect and self-esteem. Open forum discussions are required at national and state-level media and polity so that orientation and views of people may change to some extent. So, caste discrimination can only be reduced or abolished when all the interrelated parameters are addressed properly by government and individuals.

There are various scholarships and facilities for minorities and SC/ST in the Indian higher education system but they are not exploited fully due to lack of information and knowledge. With respect to the healthcare system in rural areas, the government must take decisive actions in favor of Dalits and other rural people not only for the survival of Dalits but also for the survival of the ruling party itself. Temporary shortterm campaigns and free medical camps are not adequate as the people require a permanent full-term solution. Human rights activists and NGOs often raise their voice against the injustice to the repressed people but only incidents like Payal or Rohith can open up the eyes of the leaders of our country.

\section{Conclusion}

A terrible lack of social consciousness is engulfing Indian society. Though we talk about dignity and equality in practice it is not always reflected. As a result, many people from lower caste got humiliation and disrespect in all spheres of life. By seeing the matrimonial column in newspapers, we can get an idea of ruling caste discrimination in India. Sensitive people could not withstand the discrimination and often end up their life upon failing to protest. High caste identity comes with status representation and social prestige in India. It is a common practice to judge a doctor by his last name from which one can get the caste identity to some extent.

Vertical social mobility comes from either by economic power are by marriages of lower caste bride to an upper caste groom. This complex social stratification system is pointless whenever it comes to basic needs such as healthcare, food, education, and shelter. Sense of purity and morality cannot be judged by the caste system. Purity and morality come from the actions taken, the works done and words uttered by an individual. The social evil called casteism is spreading its branches in every level and sector. But the disappointing fact is that no policy or norms or planning or agenda can uproot it. As it is embedded in the subconscious mind of civilians and is carried over generation after generation.

This paper clearly pointed out that at present Indian health service system is not at all equipped with the addressing the casteism among doctors and other healthcare service providers. An important option could be increasing the number of dalits in the different level of healthcare sector. Weather implication of this option in practical scenario is possible that needs further evaluation. Making policies that ensures the adequate representation of members of excluded communities in healthcare can certainly reduce the cultural discrimination and prejudice.

\section{References}

[1] Biswas S. What is India's caste system? BBC News [Internet]. 2019 Jun 19 [cited 2020 Jun 16]; Available from: https://www.bbc.com/news/world-asia-india-35650616.

[2] Kishore K. When caste outdoes a medical degree: Dalit doctors face discrimination in TN. Hindustan Times. 2016.

[3] SANYAL S. What one doctor's suicide says about caste discrimination in India. TRT World. 2019 Jun 7.

[4] Nayar KR. Social exclusion, caste \& health: a review based on the social determinants framework. Indian J Med Res. 2007 Oct; 126 (4): 355-63.

[5] Sankaran S, Sekerdej M, von Hecker U. The Role of Indian Caste Identity and Caste Inconsistent Norms on Status Representation. Front Psychol. 2017; 8: 487.

[6] Kumar A. Theory of uniqueness of Indian Caste System. Int J Hum Sci. 2005 Nov 1; 2.

[7] Caste System in India - Essay on Origin, History, Provisions, Acts \& Effects on Society [Internet]. Cultural India. 2018 [cited 2020 Jun 18]. Available from: https://learn.culturalindia.net/caste-system-in-india.html.

[8] Mudur GS. When the caste die was cast. The Telegraph. 2016; 26.

[9] Welle D. India's caste system: Weakened, but still influential | DW | 17.07.2017. DWCOM [Internet]. [cited 2020 Jun 16]; Available from: https://www.dw.com/en/indias-caste-systemweakened-but-still-influential/a-39718124.

[10] Shaikh M, Miraldo M, Renner A-T. Waiting time at health facilities and social class: Evidence from the Indian caste system. PloS One. 2018; 13 (10): e0205641.

[11] George S. Caste and Care: Is Indian Healthcare Delivery System Favourable for Dalits? CASTE AND CARE: IS INDIAN HEALTHCARE DELIVERY SYSTEM FAVOURABLE FOR DALITS? 2015.

[12] Kabir A, Maitrot MRL, Ali A, Farhana N, Criel B. Qualitative exploration of sociocultural determinants of health inequities of Dalit population in Dhaka City, Bangladesh. BMJ Open. 2018 14; 8 (12): e022906.

[13] Saroha E, Altarac M, Sibley LM. Caste and maternal health care service use among rural Hindu women in Maitha, Uttar Pradesh, India. J Midwifery Womens Health. 2008 Oct; 53 (5): e41-47.

[14] Srivatsan R. Reflections on discrimination and health in India. Indian J Med Ethics. 2015 Mar; 12 (1): 13-7.

[15] Bailey ZD, Krieger N, Agénor M, Graves J, Linos N, Bassett MT. Structural racism and health inequities in the USA: evidence and interventions. Lancet Lond Engl. 2017 08; 389 (10077): 1453-63.

[16] Kurian NJ. Widening economic \& social disparities: implications for India. Indian J Med Res. 2007 Oct; 126 (4): 374-80.

[17] Barik D, Thorat A. Issues of Unequal Access to Public Health in India. Front Public Health. 2015; 3: 245. 
[18] Baah FO, Teitelman AM, Riegel B. Marginalization: Conceptualizing patient vulnerabilities in the framework of social determinants of health-An integrative review. Nurs Inq. 2019; 26 (1): e12268.

[19] Robards F, Kang M, Steinbeck K, Hawke C, Jan S, Sanci L, et al. Health care equity and access for marginalised young people: a longitudinal qualitative study exploring health system navigation in Australia. Int J Equity Health. 2019 04; $18(1): 41$.

[20] Browne AJ, Varcoe CM, Wong ST, Smye VL, Lavoie J, Littlejohn D, et al. Closing the health equity gap: evidencebased strategies for primary health care organizations. Int J Equity Health. 2012 Oct 13; 11: 59.

[21] Haddad S, Narayana D, Mohindra K. Reducing inequalities in health and access to health care in a rural Indian community: an India-Canada collaborative action research project. BMC Int Health Hum Rights. 2011 Nov 8; 11 Suppl 2: S3.

[22] Yadav AK, Jena PK. Maternal health outcomes of socially marginalized groups in India. Int J Health Care Qual Assur. 2020 Mar 1; ahead-of-print (ahead-of-print): 0.

[23] Iles RA. Informal healthcare sector and marginalized groups: Repeat visits in rural North India. PloS One. 2018; 13 (7): e0199380.

[24] Kasthuri A. Challenges to Healthcare in India - The Five A's.
Indian J Community Med Off Publ Indian Assoc Prev Soc Med. 2018 Sep; 43 (3): 141-3.

[25] Baraik VK, Kulkarni PM. Health and Nutritional Status. Bridg Soc Gaps Perspect Dalit Empower New Delhi Sage. 2014; $155-68$.

[26] Thorat S, Dasgupta P. Will India's Attainment of MDGs be an Inclusive Process? Indian Institute of Dalit Studies; 2009.

[27] George S. Health for Not All: Mapping the Discriminated and Detached Terrains of Health Services in Rural India. 2015.

[28] Sonam Joshi. When doctors discriminate. Times of India. 2019.

[29] Poornima Murali. This Dalit Doctor from Tamil Nadu Survived Casteism, and a Suicide Attempt, in Medical College. 2019.

[30] National Sample Survey Organisation. Employment and Unemployment in India, July 2011-June 2012. New Delhi.: National Sample Survey Organisation, Ministry of Statistics and Programme Implementation, Government of India; 2013 Jun. (Key Results, NSS - 68th Round,). Report No.: NSS KI $(68 / 10)$.

[31] Adamson PC, Krupp K, Niranjankumar B, Freeman AH, Khan M, Madhivanan P. Are marginalized women being left behind? A population-based study of institutional deliveries in Karnataka, India. BMC Public Health. 2012 Jan 12; 12: 30. 